\title{
Psychological Wellbeing of Elderly Caregivers
}

\author{
Yong Tang \\ Sociology Department \\ Law School \\ Shenzhen University \\ Shenzhen, 518060, China
}

\begin{abstract}
In this article, the author reviews the concept "psychological wellbeing" from western and eastern perspective, and the concept of adult child caregiver, finally analysize several cases from psychological wellbeing perspective.

Keywords: Psychological wellbeing, Elderly caregiver

Psychological well being is closely related to caregivers' stress and burdens. Thus, it follows logically to review the concept. First, the author will review the concept of psychological wellbeing, and then review the various avaluable measurement scales used in the current study, namely, Affect Balance Scale (ABS), including Positive Affect Scale (PAS) and Negative Affect Scale (NAS).
\end{abstract}

\section{The Concept of Psychological Wellbeing}

Although psychological well-being has been extensively evaluated (e.g., Diener, 1984; Diener \& Emmons, 1984), when it comes to articulating the basic structure of psychological well-being, the researchers always center the discussions around the distinction between positive and negative affect and life satisfaction (Andrews \& Withey, 1976; Bradburn, 1969; Bryant \& Veroff, 1982; Diener \& Emmons, 1984; Liang, 1984,1985).

Diener (1984) grouped the definition of wellbeing into three categories. Firstly, wellbeing is defined by external criteria such as virtue or holiness. In this normative definition, wellbeing is not thought as a subjective state but rather as one possessing some desirable qualities. Secondly, social scientists have focused on the question of what leads people to evaluate their lives in positive terms. This definition of wellbeing has come to be labeled life satisfaction and relies on the respondents to determine what a good life is. Thirdly, the meaning of wellbeing comes closest to the way the term is used in everyday discourse and denotes a preponderance of positive over negative affect (Bradburn, 1969), which emphasizes pleasant emotional experiences.

In Diener et al.'s study $(1999,2003)$, they explained that the field of subjective well-being (SWB) comprises people's moods, emotions, and self-evaluative judgments that fluctuate over time and that exists between individuals and societies. General reviews of SWB can be found in Argyle (2001), Diener (1984), Diener \& Lucas (1999), and Kahneman (1999). Each of the components of SWB reflects people's evaluations of what is happening in their lives, the facets of SWB such as positive affect, lack of negative affect, and life satisfaction show some degree of independence (Andrews \& Withey 1976, Lucas et al. 1996) and therefore should be measured and studied individually.

The field of SWB has several different lines of research. Diener (1984) and Veenhoven (1984) brought these various strands in integrative reviews. Firstly, Diener (2003) concluded that sociologists and quality of life researchers who conduct surveys to determine how demographic factors influence SWB has a major influence on the field of SWB (Bradburn 1969, Andrews \& Withey 1976, and Campbell et al. 1976). Secondly, mental health researchers who extend idea of mental health beyond depression and distress to include the presence of happiness and life satisfaction have another influence on the field of SWB (Jahoda 1958). Thirdly, personality psychologists who studied the personalities of happy and unhappy people have influence on the field of SWB (Wessman \& Ricks 1966). Finally, social and cognitive psychologists who studied how adaptation and varying standards influence people's feelings of well-being have influenced the study of SWB (Brickman \& Campbell 1971; Parducci,1995).

Ryff (1995) distinguished two primary conceptions for the study of psychological wellbeing for more than 20 years. The first primary conception, traceable to Bradburn's (1969) study, distinguished psychological wellbeing between positive and negative affect and defined happiness as the balance between the two parts. The second primary conception has gained prominence among sociologists, which emphasizes life satisfaction as the key indicator of psychological well-being. Many scholars (Andrews \& McKennell, 1980; Bryant \& Veroff, 1982; Campbell, Converse, \& Rodgers, 
1976) viewed life satisfaction as a cognitive component and concluded the more affective dimension of positive functioning.

Researchers (Boey \& Chiu, 1998) in the field of psychological well being agreed that psychological wellbeing generally consists of two important aspects, namely positive and negative affect. Hence, both positive mental health (e.g. happiness and life satisfaction) and mental ill-health (e.g. anxiety and depression) are taken into account in the evaluation and measurement of psychological wellbeing. In line with this division, also considering the discussions above, we can finally conceptualize that psychological wellbeing as including both positive and negative aspects. One may ask whether positive mental health and mental ill-health are opposite poles of the same continuum of psychological wellbeing or whether they refer to two independent constructs and realities that should be measured on two independent axes. It has been proposed that positive mental health and mental ill-health are two interrelated but globally independent constructs that should be measured on two independent axes (Atienza, Stephen, \& Townsend, 2002). Here, positive affect is used to indicate mental health, and negative affect to indicate mental ill health, on the basis of the reasons provided below.

\section{Positive Affect Scale and Negative Affect Scale (PAS and NAS)}

In the 1960s, Bradburn developed a scale to measure emotional wellbeing (1969) and found that positive and negative affect items were relatively independent of one another. Bradburn proposes that happiness is composed of two separable components: positive and negative affect. Although the positive and negative affect scales were virtually uncorrelated with each other, they each showed independent and incremental correlations with a global wellbeing item (Bradburn, 1969). Bradburn hypothesizes that happiness is really a global judgment people make by comparing their negative affect with their positive affect. Thus, his Affect Balance Scale (ABS) score is derived by subtracting the sum of negative items from the sum of positive ones. Bradburn's positive affect scale asks whether the respondents, during the previous few weeks, have felt, for example, proud because someone complimented them about something they had done, or pleased about having accomplished something. The negative affect scale asks, for example, if the respondent had felt upset, depressed, or very unhappy when criticized by someone.

Humanistic psychologists such as Rogers and Maslow maintain that concern with psychopathology overlooks the positive aspects of life. Bradburn's conclusion that positive and negative affect are independent supports the long-standing argument of the humanists that psychologists focus too exclusively on the negative, and Bradburn's proposal supports the idea that absence of negative affect is not the same as the presence of positive affect. According to Bradburn's findings, attempts to enhance life satisfaction must both reduce the negative and increase positive affect.

In the present study, since stress is oriented to negative rather than positive experiences, the identification and detection of negative affect are considered essential for the maintenance and promotion of psychological wellbeing under stress. However, it is also important to increase positive affect. Therefore, this study adopts Bradburn's two-factor theory as the indicator of psychological wellbeing.

As explained in the previous chapter, the city of Guangzhou is chosen as the site for this study. The various aspects of filial piety, caregiver burden in caring for ageing parents, and their possible impacts on caregiver's psychological well-being are conceptualized in the context of a modernizing China especially in the urban regions of China. Guangzhou has been one of the leading cities in China in the path towards modernization. It has undergone the major socio-economic as well as cultural transformations accompanying modernization, and thus will definitely exhibit the corresponding problems of caregiver problems in the context of an ageing population. It thus warrants taking Guangzhou to investigate the possible relationships existing in the various domains explored in the above literature review, which might make reference to other Chinese cities undergoing similar processes of modernization. Admittedly, as China is a vast country with great regional disparity, the present study may not be entirely applicable to the rural and other less developed regions of China.

\section{Wellbeing of Adult Child Caregiver}

In addition to describing the physical and mental conditions of aged parents, subjects were invited to talk about the experiences of caring for the elderly parents, the difficulties they met during the process of taking care of the parents, the motivations of looking after parents, opinions of filial piety, the burden in the process of caring and their received support from others. In the following section, the method of content analysis was used to identify the attributes of well-being from the in-depth interview data in order to build a model of well-being of adult children caregivers theoretically.

The in-depth interview data were analyzed to identify the meaningful verbatim responses. For example, a subject reported that she divorced and took care of her father alone, and this made her feel depressed. This statement implied that caring for the elderly alone was a difficulty to the subject. Thus, the first level code "difficulty in caring process" was identified. Using this analytic process, other attributes emerged subsequently and the model of well-being of adult child caregivers was constructed. 


\section{Reciprocity (Hui Bao) for Parents' Raising Efforts}

Six subjects spontaneously reported that taking care of their aged parents was their responsibility. The statements in the case studies of F1, F2, M1, and M2 provided good examples of the importance of valuing repayment. Some western studies (Kinney, 1996; Wicclair, 2000) show that reciprocity for having been raised by one's parents is one of the motivations to care for them.

My mother did not find it easy to raise me. I never think that she is a big burden for me. I have not such thoughts. I think I should have filial respect for her. (F2)

The state propagandizes the value of filial piety. I regard it as a necessity. It is our duty. (M1)

My father cared for my son for a long time. He took him from the kindergarten to home. (F1)

\section{References}

Andrews, F.M, \& Withey, S. B. (1976). Social Indicators of Well-Being: America's Perception of Life Quality. New York: Plenum.

Andrews, F.M.,\& McKennell, A.C.(1980). Measures of Self-Reported Well-Being. Social Indicators Research, $8,127-156$.

Atienza, A.A., Stephens, M.A.P., Townsend, A.L. (2002). Dispositional Optimism, Role-Specific Stress, and the Well-Being of Adult Daughter Caregivers. Research on Aging, 24(2), 193-217.

Argyle M. (2001). The Psychology of Happiness. New York: Taylor \& Francis.

Bradburn, N. (1969). The Structure of Psychological Well-being. Chicago: Aldine.

Bryant, F. B., \& Veroff, J. (1982). The Structure of Psychological Well-Being: A Sociohistorical Analysis. Journal of Personality and Social Psychology, 43, 653-673.

Brickman, P., \& Campbell, D.T.(1971). Hedonic Relativism and Planning the Good Society. In Appley, M. H.(Ed.) Adaptation-Level Theory(pp. 287-305). New York: Academic.

Boey, K.W.,Chan, K.B. \& Ko, Y.C.(1998). Stress Coping Strategy and Psychological Well-being of Nurses: The Singapore Experience. Chinese Journal of Mental Health,11,1-20.

Campbell, A., Converse, S.E., \& Rodgers, W.L.(1976). The Quality of American Life. New York: Russell Sage Foundation.

Diener E. (1984). Subjective Well-being. Psychological Bulletin. 95:542-75.

Diener, E., \& Emmons, R. A. (1984). The Independence of Positive and Negative Affect. Journal of Personality and Social Psychology, 47, 1105-1117.

Diener E, \& Lucas, R.E. (1999). Personality and Subjective Well-being. In Kahneman et al. (1999), pp.213-29.

Diener, E., Oishi, S., Lucas, R.E. (2003). Personality, Culture, and Subjective Well-being: Emotional and Cognitive Evaluations of Life. Annual Review of Psychology. 2003,(54), 403-425.

Kahneman (1999). Objective Happiness. In D. Kahneman, E.Diener, \& N. Schwarz(Eds.). Well-being: The Foundations of Hedonic Psychology(pp.3-25). New York: Russell Sage Foundation.

Kinney, J. M. (1996). Home Care and Caregiving. In Birren, J. E. (Ed.). Encyclopedia of Gerontology, 2, (pp. 667-678). San Diego: Academic Press.

Jahoda M. (1958). Current Concepts of Positive Mental Health. In Kahneman D, Diener E, Schwarz N, (Eds). 1999. New York: Basic Books.

Liang.J.(1984) Dimensions of the Life Satisfaction Index A: A Structural Formulation. Journal of Gerontology, 39,613-622.

Liang, J. (1985). A Structural Integration of the Affect Balance Scale and the Life Satisfaction Index A. Journal of Gerontology, 40, 552-561.

Lucas, R.E, Diener, E, \& Suh, E. (1996). Discriminant Validity of Well-being Measures. Personal. Social Psychology. 71:616-28.

Parducci, A. (1995). Happiness, Pleasure and Judgment: The Contextual Theory and Its Applications. Mahwah, NJ: Erlbaum.

Wessman, A.E.,\& Ricks, D.R. (1966). Mood and Personality. New York: Holt, Rinehart \& Winston.

Wicclair, M. R. (2000). Caring for Frail Elderly Parents: Past Parental Sacrifices and the Obligations of Adult Children. Social Theory \& Practice, 16(2), 163-190. 